\title{
Image transfer based on exposure sequence and time gap between exposures in sport sponsorship: Testing of primacy and recency effects
}

\author{
Hyungil Kwon \& Mihwa Choi* \\ Chung-Ang University
}

\begin{abstract}
[Purpose] The purpose of the study was to examine the effect of exposure sequence and time gap between two exposures in image transfer in the context of sport sponsorship. [Methods] To accomplish the purpose of the study, one preliminary study and one main study were performed. The sample was drawn using a convenience sampling (33 for preliminary study and 120 for the main study). The data were analyzed using one sample t-test, repeated measure ANOVA(mixed design). [Results] The data for the main study indicated that the mean of the post-test was statistically higher than that of pre-test, which indicated that the image of the sporting event was transferred to the image of the brand Dell. This indicated that the image transfer actually took place although image similarity between sporting events and sponsoring brand was not conditioned. The hypotheses of the study were tested using a mixed design with exposure sequence and time gap between exposures as two between subject factors. The results indicated that the interaction was statistically significant. When two sponsorship information were given consecutively, the first sport event's image was transferred more than the image of the secondly presented sport event, which indicated primacy effect. However, when the two sponsorship information was given with two days time gap, the image of the second sport event was transferred more than the first sport event's image, which indicated a recency effect. [Conclusions] Two meaningful findins were delivered through the current study. First, even when there was no image similarity between sport event and brand, image transfer took place through sponsorship arrangement. Second, if primacy and recency effects are properly incorporated, image transfer can be achieved in a more effective way in sponsorship context.
\end{abstract}

Key words: Sport sponsorship, Image transfer, Primacy effect, Recency effect

\section{서 론 \\ 스포츠 스폰서십에 참여하는 기업의 궁극적인 목적 중 하나는 긍정적인 이미지를 가지고 있는 올림픽이나 월드 컵 등과 같은 스포츠 이벤트에 기업의 제품 및 서비스를}

논문 투고일 : 2019,03,04

논문 수정일 : 2019. 04. 13.

게재 확정일 : 2019. 05. 07.

* 교신저자 : 최미화(cs_4u@naver.com).

* 이 논문은 2019 년도 중앙대학교 연구장학기금 지원에 의한 것임.
연관시켜 기업의 이미지를 향상 또는 개선하기 위한 것이 다. 이 외에도 스포츠 이벤트의 후원이라는 친사회적 행 동을 통해 소비자들로부터 기업에 대한 긍정적인 태도와 감정을 유발시키려는 목적이 있다(Gwinner, 1997). 즉, 스포츠 스폰서십은 기업의 인지도 향상, 이미지 강화, 제 품 사용기회 및 판매 기회 확대 등의 다양한 기대 효과를 가진다(McCracken, 1989; Kim, Cho \& Kim, 2010).

스포츠를 활용한 스폰서십은 국내에서도 활발하게 이 루어지고 있다. 그 중, $\mathrm{KEB}$ 하나은행은 최근 적극적인 스폰서십으로 미디어의 주목을 받고 있다. $\mathrm{KEB}$ 하나은 
행은 2018 평창동계올림픽대회의 공식 은행업무 후원 사로 활동을 하였으며 이에 앞서 2017년부터 국내 프 로축구 $\mathrm{K}$ 리그의 타이틀 스폰서로 활동을 하고 있다. 특 히 K리그 타이틀 스폰서로서 획득한 경제적 효과는 총 639 억 1473 만 원으로 나타나 $\mathrm{K}$ 리그의 스폰서 중에서 가 장 큰 미디어 노출 효과를 누린 것으로 나타났다(Kwon, 2017).

Gladden과 Wolfe(2001)는 스포츠 스폰서십의 본질 적인 목적은 스폰서십을 실행하는 기업과 스폰서십을 받 는 스포츠 이벤트 사이의 이미지 속성 공유에 의한 브랜 드 인지도 상승과 이미지 증진에 있다고 하여 이미지 효 과를 강조하였다. 앞선 $\mathrm{KEB}$ 하나은행의 사례와 같이 스 폰서십을 통한 기업의 경제적 효과는 스포츠 이벤트의 긍 정적인 이미지가 브랜드로 전이된 결과라고 할 수 있다. Gwinner와 Eaton(1999)은 스폰서십을 실행하는 브랜 드가 효과적인 이미지 전이를 위해서는 브랜드가 가지고 있는 이미지와 유사한 이미지를 소유한 이벤트를 선정할 것을 제안하였다. 이 제안은 다른 연구자들을 통해서도 지지 되었는데 하나의 브랜드와 하나의 이벤트 간의 이미 지 유사성과 관련된 연구가 진행되었다(Kim, Lee \& Lee, 2006; Lee \& Hyun, 2010; Kim, Shim \& Kim, 2010).

스폰서십을 통한 이미지 전이에 대한 사전연구에서는 하나의 브랜드가 하나의 스포츠 이벤트를 후원하는 가 정에서 이루어졌다. 하지만 현실적으로 한 브랜드가 하나 의 스포츠 이벤트만을 후원하는 경우는 드물다. 예를 들어 $\mathrm{KEB}$ 하나은행이 2018 평창동계올림픽대회 공식 스폰 서로 활동하면서 국내 프로축구 $\mathrm{K}$ 리그의 타이틀 스폰서 로 활동하고 비인기 종목인 대한루지연맹을 후원하며 이 외에도 다양한 스폰서십을 실행하고 있다(Hwang \& $\mathrm{Kim}, 2018)$. 뿐만 아니라 2018 평창동계올림픽대회에서 $\mathrm{KEB}$ 하나은행과 같이 공식스폰서로 활동했던 한화그룹 의 경우는, KLPGA 골프 대회와, 마라톤대회 그리고 기 업주최의 유일한 사격대회에도 스폰서로 참여하고 있다 (Hanwha, 2018).

하지만 스포츠 스폰서십을 통한 이미지 전이 연구에서 는 이미지가 상이한 스포츠 이벤트들을 후원하는 순서에 따라 어떠한 이미지가 스폰서 브랜드에 전이되는 지에 대 한 연구가 되어있지 않은 상태이다. 이러한 제한적인 연 구의 결과로 인하여 이미지가 상이한 여러 이벤트를 후 원하게 되는 경우, 후원의 효과를 최대화하기 위한 전략
적 의사결정에 사용될 수 있는 정보가 부족한 실정이다. 따라서 본 연구에서는 선행연구에서 제시하고 있는 초 두효과와 최신효과의 이론적 근거를 바탕으로 두 개의 상 이한 이미지의 스포츠 이벤트를 후원할 때, 처음 후원하 는 이벤트의 이미지가 브랜드로 전이가 되는지 혹은 두 번째로 후원하는 이벤트의 이미지가 브랜드로 전이되는 지를 파악하고자 한다. 본 연구의 결과는 스폰서 기업이 다양한 스포츠 이벤트를 후원할 때 기업이 구축하고자 하는 이미지에 맞춰 후원하는 스포츠 이벤트를 전략적으 로 선택하는데 중요한 정보를 제시할 수 있을 것이라 기 대된다.

\section{이론적 배경 및 가설 설정}

선행연구에서 메시지의 제시 순서에 따른 정보 회상의 차이를 설명하는 데에는 두 가지 상반된 효과가 사용되고 있다. 이는 처음에 제시된 메시지가 더 잘 회상된다는 초 두효과와 나중에 제시된 메시지가 더 잘 회상된다는 최신 효과이다(Kim, 2011; Park, Kim \& Kim, 2012; Jung, 2016; Jung, 2009; Choi, 2003; Miller \& Campbell, 1959).

Asch(1946)는 두 사람의 성격에 대한 정보를 제시하 고 누구에게 더 긍정적인 반응을 보이는지에 대한 실험을 진행하였다. 두 사람에 대해 기록한 글을 읽고 각각에 대 한 인상을 적도록 하였다. A는 '똑똑하다', '근면하다', '충 동적이다', '비판적이다', '고집 스럽다', '질투심이 많다' 순 으로 소개 하였고, $\mathrm{B}$ 는 '질투심이 많다' ' '고집 스럽다', '비 판적이다', '충동적이다', '근면하다', '똑똑하다' 순으로 소 개 하였다. 실제로는 똑같은 내용을 순서만 다르게 제시 하였지만 실험 참가자들은 $\mathrm{A}$ 에 대해 더 긍정적인 반응 을 보였다. 이러한 연구결과를 토대로 의사전달을 통한 설득에 있어서 초두효과가 나타나는 현상을 의미 변화 가 설(Meaning Change Hypothesis)을 바탕으로 설명하 였다. 앞에 제시되는 메시지에 의해 일찍 형성된 인상이 이후 판단의 근거가 되어 다음 인상 형성과정에 영향을 미친다는 것이다. 이외에도 선후 학습 간의 간섭효과를 설명하는 간섭이론(Interference Theory)에서 선행학습 이 후행학습의 기억하는 과정을 방해 한다는 학습이론, 메시지가 전달될 때 처음 것에 가장 많은 주의를 집중하 고 뒤로 갈수록 주의집중이 줄어든다는 주의감소이론 등 
이 초두효과를 지지하고 있다(Choi, 2003; Choi, 2008). 이에 스폰서십 상황에서 한 개의 브랜드가 서로 다른 이 미지를 가진 두 개의 이벤트를 후원하는 경우, 나중에 노 출되는 이벤트의 이미지 보다 먼저 노출되는 이벤트의 이 미지가 브랜드에 전이되는지를 확인하고자 한다.

본 연구에서는 다양한 스포츠 종목이 줄 수 있는 가외 변인적 영향을 최소화하기 위하여 단일 종목의 스포츠 이 벤트 두 개(세계수영선수권대회와 세계사격선수권대회) 를 선정하였다. 그리고 선정된 두 종목에 대한 개인적 선 호의 영향을 배제하기 위하여 두 개의 이벤트를 번갈아 제시하는 식으로 가설을 설정하였다. 본 연구에서는 이벤 트 노출 순서와 이벤트 노출 간격을 연구의 독립변인으로 포함시키고 이 변인들이 이미지 전이에 미치는 영향을 살 펴보기 위하여 가설을 각각 설정하였다.

가설 $1 \mathrm{a}: \mathrm{A}$ 브랜드와 $\mathrm{E} 1$ 이벤트의 결합을 먼저 노출 시 킨 후 곧바로 $\mathrm{A}$ 브랜드와 $\mathrm{E} 2$ 이벤트의 결합을 노출시켰을 때 초두효과로 인해 $\mathrm{E} 1$ 이벤트 이미지가 $\mathrm{A}$ 브랜드로 더 많 이 전이 될 것이다.

가설 $1 \mathrm{~b}: \mathrm{A}$ 브랜드와 $\mathrm{E} 2$ 이벤트의 결합을 먼저 노출 시 킨 후 곧바로 $\mathrm{A}$ 브랜드와 $\mathrm{E} 1$ 이벤트의 결합을 노출시켰을 때 초두효과로 인해 $\mathrm{E} 2$ 이벤트 이미지가 $\mathrm{A}$ 브랜드로 더 많 이 전이 될 것이다.

제시된 두 개의 가설은 이미지 전이의 메카니즘이 인 상형성과 기억 혹은 회상의 메카니즘과 유사하다는 가 정 하에서 제시되었다. 하지만 초두효과가 일관되게 나 타나는 현상은 아니라는 지적도 존재한다. 사회심리학자인 Miller와 Campbell(1959)의 연구가 이 지적을 뒷받침 해 주고 있다. Miller와 Campbell(1959)은 실험상황을 모 의재판 과정으로 설정하였고 실험참가자들을 네 개의 그룹으로 나누었다. 첫 번째 그룹은 두 개의 메시지를 연 속해서 들은 후 바로 판단하게 하고 두 번째 그룹은 두 개 의 메시지를 연속해서 들은 후 일주일 후에 판단하게 하 였다. 첫 번째 그룹에서는 하위요인으로 분류된 태도와 회상 두 개 모두에서 통계적으로 유의미한 결과를 얻지 못하였고, 두 번째 그룹에서 태도에서만 초두효과를 짐작 하게 하는 유의미한 결과가 나왔다.

세 번째 그룹과 네 번째 그룹은 한 개의 메시지를 들은 후 일주일 후에 다른 한 개의 메시지를 들었다. 다만 세 번째 그룹은 마지막 메시지를 들은 후 바로 판단하게 하
고 네 번째 그룹은 다시 일주일 후에 판단하게 하였다. 세 번째 그룹은 태도와 회상 모두에서 최신효과를 짐작하게 하는 유의미한 결과 나왔고, 네 번째 그룹은 회상에서만 최신효과를 짐작하게 하는 유의미한 결과가 나왔다. 결 과적으로 두 가지의 정보를 한꺼번에 전달 받은 상황에서 는 초두효과를 짐작할 수 있으며, 정보를 듣는 간격(시 간)이 있는 상황에서는 최신효과를 짐작 할 수 있는 것으 로 판단된다. 특히 세 번째 그룹에서 태도와 회상 모두에 서 다른 그룹보다 유의수준이 높았는데 이는 가장 최근에 들은 정보가 먼저 들은 정보보다 더 기억에 잘 남거나 설 득에 효과적이라는 최신효과를 예측할 수 있다(Nam \& Chung, 2016; Song et al., 2014).

위의 실증적인 연구들의 결과를 바탕으로 스폰서십을 실행하는 기업이 두 개의 다른 이미지를 보유한 이벤트를 순차적으로 충분한 시간적 간격을 두고 스폰서 했을 때, 이미지 전이에서 최신효과가 나타나는 지를 확인하고자 다음과 같은 가설을 설정하였다.

가설 $2 \mathrm{a}: \mathrm{A}$ 브랜드와 $\mathrm{E} 1$ 이벤트의 결합을 먼저 노출 시 킨 후 간격(시간)을 두고 $\mathrm{A}$ 브랜드와 $\mathrm{E} 2$ 이벤트의 결합을 노출시켰을 때 최신효과로 인해 $\mathrm{E} 2$ 이벤트 이미지가 $\mathrm{A}$ 브 랜드로 더 많이 전이 될 것이다.

가설 $2 \mathrm{~b}: \mathrm{A}$ 브랜드와 $\mathrm{E} 2$ 이벤트의 결합을 먼저 노출 시 킨 후 간격(시간)을 두고 $\mathrm{A}$ 브랜드와 $\mathrm{E} 1$ 이벤트의 결합을 노출시켰을 때 최신효과로 인해 $\mathrm{E} 1$ 이벤트 이미지가 $\mathrm{A}$ 브 랜드로 더 많이 전이 될 것이다.

\section{연구방법}

\section{연구대상}

본 연구는 국내에 거주하는 내국인 중 2018년 현재 20세 이상의 성인을 모집단으로 설정 하였다. 본 연구를 위한 표본은 시간과 비용의 제약 및 통제의 용이성을 고 려하여 비확률 표본추출방법(non-probability) 중 편의 표본추출법(convenience sampling method)을 통해 연 구대상자를 선정 하였다. 서울 소재의 모 단체에서 주최 한 세미나에 참석한 성인을 대상으로 자료를 수집하였다. 결과의 내적타당성을 저해할 수 있는 학습효과를 방지하 기 위하여 사전 조사와 본 조사에 중복 참여하는 대상자 
가 없도록 통제하였다.

스포츠 이벤트의 노출 순서에 따라 어떠한 스포츠 이 벤트의 이미지가 브랜드에 전이되는지 비교하기 위하여 선정된 연구대상자들을 네 개의 그룹으로 분류하였다. 많 은 연구 참여자들을 한 자리에 모이게 하는 것이 어려워 섭외가 되고 접촉이 되는 연구 대상자들의 순서에 따라 집단을 분류하였다. 이때 2 일의 시간이 필요한 3 그룹, 4 그룹으로 먼저 배정하였으며 설문의 진행 방식을 설명하 던 중 2 일 후에 브랜드 이미지 측정이 어렵다고 응답한 연구대상자는 1 그룹, 2 그룹으로 배정하였다. 본 연구의 주된 자료분석 방법인 분산분석의 충분한 관측검정력 을 확보하기 위하여 각 그룹 마다 30 명 이상의 연구대상 자가 할당되었다.

\section{조사도구}

브랜드와 스포츠 이벤트의 친숙도는 Machleit과 Allen과 Madden(1993)이 개발한 세 개의 문항을 사용 하여 7점 척도로 측정하였다. 브랜드와 스포츠 이벤트가 가지고 있는 이미지를 측정하기 위해서는 각각의 이미 지를 잘 묘사할 수 있는 형용사가 필요하다. 이를 위해 Aaker(1997)의 연구에서 사용한 42개의 형용사와 Graeff (1996)의 연구에서 사용한 32개의 형용사 중 Aaker (1997)의 42개의 형용사와 중복되는 형용사를 제외한 11 개의 형용사를 합하여 총 53 개의 형용사가 이미지 선 정에 사용되었다. 53 개의 형용사가 브랜드와 이벤트에 대해 얼마나 잘 묘사하고 있는지를 7점 척도로 측정하 였다.

\section{연구설계}

예비 조사 일 회와 본 조사 일 회를 실시하였다. 예비 조사는 본 조사에서 사용하게 될 한 개의 스폰서 브랜드 와 두 개의 스포츠 이벤트 선정과 스폰서 브랜드, 스포츠 이벤트를 나타내는 형용사 선택을 위해 진행되었다.

선행 연구에 따르면 이미지로만 기억되거나 언어적 요 소로만 기억된 정보보다 이미지와 언어적 요소가 복합이 되어 기억된 정보가 더 우월하게 회상된다(Ryoo et al., 2015; Park et al., 2012). 따라서 본 연구에 사용된 스폰 서십 자료는 신문 이름과 게재 날짜, 기자 성명 및 이메일 등을 기입하여 실제 인터넷 기사를 출력한 것처럼 보이도 록 하였다. 스폰서십의 정보를 담은 자료는 $\mathrm{A} 4$ 용지에 컬
러로 출력하여 연구에 사용하였다.

본 연구에서는 한 개의 스폰서십 기사를 읽는데 충분 한 시간이라고 판단되는 약 이분 정도의 시간이 주어졌 다. 연구대상자들에게 연구자가 제작한 자료를 개별적 으로 한 부씩 제공하였고, 설명을 마친 후 자료를 곧 바로 회수 하였다. 1 그룹과 2 그룹은 별도의 시간적인 간격 없 이 곧바로 다른 스폰서십 정보가 담긴 인터넷 뉴스보도 자료 형태의 자료를 제시하고 앞선 스폰서십 정보에 대한 설명과 동일하게 진행하였다. 두 번째 스폰서십에 대한 설명을 마친 후 자료를 회수하고 별도의 시간적인 간격 없이 브랜드의 이미지를 측정하도록 하였다.

망각에 관한 선행 연구에 따르면 사람들은 정보 습득 후 2 일이 경과되면 습득된 정보의 대부분을 잊어버리게 되며 오직 27.8\%만을 기억한다(Sol, 2016). 하지만 본 연구에서 연구대상자들에게 제 공되는 정보의 양이라는 것이 딱히 존재하지 않기 때문에 2 일 후에도 상당 부분을 기억할 수 있을 것이라 기대되었다. 이에 3그룹과 4그룹 은 첫 번째 스포츠스폰서십 정보를 제공 한 후 자료와 설 문지를 모두 회수 하고 2 일 후 두 번째 스포츠스폰서십 정보를 제공하였다. 스폰서십에 대한 설명이 종료되면 자 료를 즉시 회수하고 시간적인 간격 없이 바로 브랜드 이 미지를 측정하도록 하였다. 두 개의 스폰서십 정보를 설 명하는데 소요된 시간은 모든 그룹에 동일하게 적용되었 다. 같은 실험참여자가 동일한 이벤트에 2회 이상 노출이 되면서 생길 수 있는 이월효과를 방지하기 위하여 가설마 다 다른 연구대상자가 참여하도록 하였다.

\section{자료처리}

본 연구에서 모든 자료처리는 SPSS 23 통계 프로그램 을 이용하여 분석하였다. 친숙도 점검을 위하여 일표본 t-test를 실시하였고 모든 측정항목에 대한 평균 및 표 준편차를 산출하였다. 자료의 정규성을 검정하기 위하여 기술통계분석을 실시하였으며 가설 검증은 혼합설계 (Mixed Design)를 사용하였다.

\section{예비 조사}

본 연구에서 사용할 스포츠 이벤트는 예비 조사를 통 하여 동일한 친숙도 정도를 나타내는 스포츠 이벤트로 선 정 하였다. 단, 어떤 스포츠 이벤트의 이미지가 스폰서 브 랜드로 전이 되었는지 확인하기 위하여 서로 다른 이미지 
를 가진 스포츠 이벤트를 선정하였다.

이를 위해 총 35 명을 대상으로 설문을 실시하였으며 회수한 설문지 중 미 기입으로 인해 사용이 부적절하다고 판단되는 두 부를 제외한 33 부를 분석에 사용하였다.

예비 조사 대상자들의 인구통계학적 특성은 성별은 남 자 $39.4 \%(\mathrm{n}=13)$, 여자 $60.6 \%(\mathrm{n}=20)$ 이며 나이는 평 균 39.6세로 나타났다.

스폰서 브랜드는 본 연구에 사용되는 스포츠 이벤트를 한 번도 후원한 경험이 없는 브랜드로 선정 하였다. 이는 연구대상자에게 실험상황에서 제시되는 가상의 스폰서 십을 통해서만 이미지 형성이 되도록 하기 위한 것이다. 이와 같은 기준으로 본 연구를 위한 스폰서 브랜드는 다 국적 컴퓨터 기업인 DELL로 선정을 하였다. 또한 스포 츠 이벤트는 세계태권도선수권대회, 세계수영선수권대 회, 세계사격선수권대회, 사대륙 피겨스케이팅 선수권대 회를 대상에 포함시켰다. 이 이벤트들은 스포츠종목의 인기나 이벤트의 크기가 상당히 유사하며 실재 존재하는 이벤트라는 기준으로 선정이 되었다. 이를 대상으로 하여 동일한 조건에서 단지 제시되는 순서에 따라 이벤트의 이 미지가 스폰서 브랜드로 전이되는지 확인하기 위하여 같 은 수준의 친숙도를 가진 스포츠 이벤트를 선정하였다.

\section{스폰서 브랜드와 스포츠 이벤트의 친숙도 조사}

사전연구에서 실험주제의 친숙도가 높을수록 초두효 과가 높게 나타났다(Luna, 1961). 따라서 스포츠 이벤트 의 이미지가 브랜드로 전이 되는데 있어서 친숙도에 의한 영향을 배제하기 위하여 통계적으로 같은 수준의 친숙도 를 보유하고 있는 스포츠 이벤트를 사용하고자 하였다. 본 연구에서 측정한 친숙도는 스포츠 종목에 대한 친숙 도가 아니라 스포츠 이벤트에 대한 친숙도이다. 따라서 수영이라는 종목에 친숙한 경우라도 세계수영선수권대 회라는 이벤트에는 친숙하지 않을 수 있다. 친숙도 측정 결과는 〈Table 1〉에 제시하였다.

Table 1. Familiarity of the sponsor brands and the sporting event

\begin{tabular}{cccccc}
\hline \hline & DELL & Taekwondo Swimming & Shooting & $\begin{array}{c}\text { Figure } \\
\text { skating }\end{array}$ \\
\hline$M$ & 3.35 & 1.75 & 1.71 & 1.80 & 2.11 \\
\hline \hline
\end{tabular}

본 연구에서는 스포츠 이벤트의 이미지가 DELL로 전 이되는 것을 보는 것이기 때문에 DELL에 대한 친숙도가 미치는 영향에 대해서는 고려되지 않았다. 왜냐하면 어 떤 스포츠 이벤트에 대해 생각하고 있던 이미지가 스폰서 브랜드로 전이 되는데 있어 그 스폰서 브랜드의 기존 이 미지가 큰 영향을 끼칠 수 있다는 사전연구의 결과가 존 재하지 않으며 사전연구에서도 기존의 부정적 이미지를 가지고 있었던 브랜드가 긍정적 이미지를 가진 스포츠 이 벤트와 공익연계마케팅에 참여하면서 긍정적으로 이미 지가 바뀐 경험적 증거가 있다 (Kwon \& Cho, 2017). 하 지만 브랜드 사용경험 유, 무가 이미지 전이에 미칠 수 있 을지 모르는 영향을 최소화하기 위하여 본 조사 시에 브 랜드 사용 경험자가 전체 네 개의 그룹에 고르게 분포되 도록 하였다.

\section{스폰서 브랜드와 스포츠 이벤트의 이미지를 나타 내는 형용사 선택}

브랜드와 스포츠 이벤트가 가지고 있는 이미지를 측 정하기 위해서 53개의 형용사가(Aaker, 1997; Graeff, 1996) 앞서 선택한 한 개의 브랜드와 네 개의 스포츠 이 벤트에 대해 얼마나 잘 묘사하고 있는지를 7점 척도로 점 수화하여 측정하였다. 점수를 매긴 형용사들 중 브랜드에 서 가장 높은 점수를 얻은 세 개와 각각의 스포츠 이벤트 에서 가장 높은 점수를 얻은 세 개씩을 선정하였다. 이때 브랜드와 스포츠 이벤트의 이미지를 잘 묘사하는 것으로 선정된 형용사 중에서 중복되는 형용사가 있다면 중복되 는 형용사는 모두 제외시키고 다음으로 높은 점수를 얻은 형용사를 선택하였다.

세계태권도선수권대회와 세계사격선수권대회는 각각 의 스포츠 이벤트를 나타내는 것으로 채택된 형용사중 상위 5 위 안에 공유하는 형용사가 네 개로 나타났다. 이 는 두 개의 스포츠 이벤트의 이미지가 많이 유사하다는 것이고, 이에 따라 이미지의 중복성을 피하기 위하여 차 점의 세계수영선수권대회를 선택하였다. 각각의 이미지 형용사 선택에 앞서 세계수영선수권대회와 세계사격선 수권대회에 대한 친숙도를 점검한 결과 통계적으로 동 일한 것으로 나타났다 $(t=.48, d f=32, p=.63)$. 이에 두 개의 스포츠 이벤트에서 선정된 형용사들의 평균값을 〈Table 2〉에 제시하였다. 선정된 형용사들 간의 내적 일 관성이 요구되는 자료가 아니므로 자료의 신뢰도 검증 은 실시하지 않았다. 
Table 2. Mean value of the brand adjectives and the event adjectives

\begin{tabular}{lccc}
\hline \hline & & & \\
& & & \\
& & & \\
& & & \\
\hline \multirow{3}{*}{ DELL } & Successful & 5.48 & .94 \\
\cline { 2 - 4 } & Contemporary & 5.27 & 1.35 \\
\cline { 2 - 4 } & Creative & 5.18 & 1.29 \\
\hline \multirow{3}{*}{$\begin{array}{l}\text { FINA World } \\
\text { Championship }\end{array}$} & Cheerful & 5.12 & 1.17 \\
\cline { 2 - 4 } & Wholesome & 4.97 & 1.05 \\
\cline { 2 - 4 } $\begin{array}{lcc}\text { ISSF World } \\
\text { Shooting } \\
\text { Championship }\end{array}$ & Cactive & 4.79 & 1.47 \\
\cline { 2 - 4 } & Formal & 5.36 & 1.60 \\
\cline { 2 - 4 } & Delicate & 4.94 & 1.54 \\
\hline \hline
\end{tabular}

\section{본 조사}

본 조사를 위해 127 명을 대상으로 설문을 실시하였다. 분석에는 1 차 설문에만 응답하고 2 차 설문에 응답하지 못한 네 부와 이중표기로 인해 분석에 부적절한 세 부를 포함한 총 일곱 부를 제외한 120 부를 사용하였다. 본 조 사를 위한 연구대상자들의 인구통계학적인 특성을 살펴 보기 위하여 빈도분석을 실시하였으며 결과는 〈Table 3〉 과 같다. 이중 스폰서 브랜드로 선정된 DELL의 사용경 험이 있다는 응답자는 52 명으로 1 그룹 10 명, 2 그룹 12 명, 3그룹 19명, 4그룹 11명으로 비교적 고르게 분포되 어 있는 것으로 나타났다.

본 조사에서는 총 네 개의 그룹으로 나누어진 연구대 상자에게 두 번에 걸쳐 브랜드 DELL에 대한 이미지를 측 정하였다. 이미지 측정은 예비조사를 통해 브랜드 DELL 의 이미지와 각각의 스포츠 이벤트 이미지를 잘 묘사하는 것으로 선정된 총 아홉 개의 형용사를 사용하였다(DELL 이미지 형용사 세 개, 세계수영선수권대회 이미지 형용사 세 개, 세계사격선수권대회 이미지 형용사 세 개). 먼저 스폰서십 전(Pre-test)의 브랜드 DELL에 대한 이미지를 측정하고 브랜드 DELL이 두 개의 스포츠 이벤트에 각각 스폰서십을 실행하는 정보를 확인한(Post-test) 후 다시 브랜드 DELL에 대한 이미지를 측정하였다.

이때 브랜드 DELL의 이미지 측정 시 노출되는 스포츠 이벤트의 순서에 따라 형용사의 위치를 다르게 제시 하였 다. 예를 들어 세계사격선수권대회의 정보를 먼저 제시하 는 2 그룹과 4 그룹에는 세계사격선수권대회의 이미지를
Table 3. Demographic data of the subject

\begin{tabular}{|c|c|c|}
\hline & Variable & Rate $(\%)$ \\
\hline \multirow{2}{*}{ Gender } & Male & $71(59.2)$ \\
\hline & Female & $49(40.8)$ \\
\hline \multirow{4}{*}{ Age } & $20 \mathrm{~s}$ & $20(16.6)$ \\
\hline & $30 \mathrm{~s}$ & $23(19.2)$ \\
\hline & $40 \mathrm{~s}$ & $54(45.0)$ \\
\hline & Over 50s & $23(19.2)$ \\
\hline \multirow{3}{*}{$\begin{array}{l}\text { Location of } \\
\text { Residence }\end{array}$} & Seoul & $98(81.7)$ \\
\hline & Gyeonggi & $16(13.3)$ \\
\hline & The others & $6(5.0)$ \\
\hline \multirow{4}{*}{ Occupation } & Salarymen & $90(75.0)$ \\
\hline & Student & $9(7.5)$ \\
\hline & No job & $8(6.7)$ \\
\hline & Others & $13(10.8)$ \\
\hline \multirow{4}{*}{$\begin{array}{l}\text { Period of } \\
\text { use of the DELL }\end{array}$} & None & $68(56.7)$ \\
\hline & Less than 6 months & $1(0.8)$ \\
\hline & 6 months $\sim 1$ year & $6(5.0)$ \\
\hline & Over 1 year & $45(37.5)$ \\
\hline
\end{tabular}

묘사하는 것으로 선정된 세 개의 형용사(차분한, 격식있 는, 섬세한)가 세계수영선수권대회의 이미지 형용사(쾌 활한, 건전한, 활발한) 보다 앞에 제시된 설문지를 사용 하였다. 이를 통해 해당 형용사가 앞에 위치하면서 생길 수 있는 가외변인적 효과를 모든 경우에 동일하게 적용시 켜 이에 대한 오염을 방지하였다.

가설 $1 \mathrm{a}$ 와 $1 \mathrm{~b}$ 검정을 위한 1 그룹과 2 그룹은 스폰서십 전의 브랜드 DELL에 대한 이미지를 측정 (Pre-test)하 고 스폰서십을 실행하는 정보를 모두 확인한 후 바로 다 시 브랜드 DELL에 대한 이미지를 측정(Post-test) 하였 다. 그러나 가설 $2 \mathrm{a}$ 와 $2 \mathrm{~b}$ 를 검증하기 위해 참여하는 3 그 룹과 4그룹은 스폰서십 전의 브랜드 DELL에 대한 이미 지를 측정 (Pre-test)한 후 브랜드 DELL이 한 개의 스포 츠 이벤트(가설 $2 \mathrm{a}$ 의 경우에는 세계수영선수권대회, 가 설 $2 \mathrm{~b}$ 의 경우에는 세계사격선수권대회)에 스폰서십을 실 행하는 정보를 확인 하고 다음 정보(가설 $2 \mathrm{a}$ 의 경우에는 세계사격선수권대회, 가설 $2 \mathrm{~b}$ 의 경우에는 세계수영선수 권대회)는 2 일 후에 확인(Post-test)하였다. 다시 말해, 스폰서십 전(Pre-test)의 브랜드 DELL에 대한 이미지 를 측정한 후 2 일 후에 브랜드 DELL(Post-test)의 이미 지를 다시 측정을 하였다. 


\section{연구결과}

\section{자료점검 및 기술통계}

스폰서십 전(Pre-test)과 스폰서십 후(Post-test)의 자료에 대해 왜도와 첨도를 사용하여 자료의 정규성을 확인하였다. 왜도와 첨도의 추정값이 -1 과 +1 사이에 위 치할 경우 자료의 정규성을 가정하는데 (Kline, 1998), 결 과값이 위의 범위에 포함되어 자료가 정상분포를 이루 고 있는 것을 확인하였다〈Table 4〉.

Table 4. Descriptive statistics result from the Pre-test and the Post-test

\begin{tabular}{cccccc}
\hline \hline & & & & & \\
& & & & \\
& & & & \\
& & & & \\
Pre-test & DELL & 5.46 & .93 & -.46 & .29 \\
\cline { 2 - 6 } & Swimming & 4.76 & 1.02 & -.28 & -.06 \\
\cline { 2 - 6 } & Shooting & 4.58 & 1.01 & -.27 & .19 \\
\hline \multirow{3}{*}{ Post-test } & DELL & 5.48 & 1.17 & -.84 & .85 \\
\cline { 2 - 6 } & Swimming & 5.35 & 1.11 & -.65 & .01 \\
\cline { 2 - 6 } & Shooting & 4.80 & 1.24 & -.19 & -.67 \\
\hline \hline
\end{tabular}

본 연구에서 사용된 스포츠 이벤트는 남자 종목과 여 자 종목이 모두 존재하는 종목으로 선정되었다. 이는 본 연구의 결과가 종목의 성별에 의한 특정한 선호에 의해 오염되는 것을 방지하기 위함이었다. 가설의 검증이 이루 어지기 전에 먼저 스폰서십에 의한 이미지 전이가 성별에 따라 다르게 나타나지 않는 지를 재확인하였다. 이를 위 하여 이미지 전이에 대한 성별의 조절효과가 존재하는 지 를 혼합설계(Mixed Design)를 통해 알아보았다. 분석 결과, 이미지 전이의 개체내 효과는 성별에 의해 조절되 지 않는 것으로 나타나 본 연구의 결과가 성별이라는 가 외변인으로부터 안전한 것으로 나타났다〈Table 5〉. 본 연구는 반복회수가 사전(Pre-test)과 사후(Post-test), 이 회인 경우로 구형성 검정이 되지 않는다. 따라서 Greenhouse-Geisser의 통계량을 제시하였다.

스포츠 이벤트의 종목에 따른 가외변인적 효과가 존 재하는 지를 혼합설계 (Mixed Design)를 통해 알아보았 다. 아래〈Table 6〉에 제시되었듯, 이미지 전이의 정도 는 스포츠종목에 의해 조절되지 않는 것으로 확인되었다.
Table 5. Moderating effect of gender on the image transfer

F $\quad p \quad \eta p 2$ Power

\begin{tabular}{cccccc}
\hline $\begin{array}{c}\text { Factor 1 } \\
\text { (Pre, Post) }\end{array}$ & $\begin{array}{c}\text { Greenhouse- } \\
\text { Geisser }\end{array}$ & 31.581 & .000 & .118 & 1.000 \\
\hline $\begin{array}{c}\text { Factor 1 } \\
* \text { Gender }\end{array}$ & $\begin{array}{c}\text { Greenhouse- } \\
\text { Geisser }\end{array}$ & .004 & .950 & .000 & .050 \\
\hline \hline
\end{tabular}

Table 6. Moderating effect of the sporting event on the image transfer

F $\quad p \quad \eta p 2$ Power

\begin{tabular}{lcccccc}
\hline \multirow{2}{*}{ 1Group } & $\begin{array}{c}\text { Factor 1 } \\
\text { (Pre, Post) }\end{array}$ & $\begin{array}{c}\text { Greenhouse- } \\
\text { Geisser }\end{array}$ & 29.492 & .000 & .200 & 1.000 \\
\cline { 2 - 7 } & $\begin{array}{c}\text { Factor 1 } \\
* \text { Event }\end{array}$ & $\begin{array}{c}\text { Greenhouse- } \\
\text { Geisser }\end{array}$ & .012 & .913 & .000 & .051 \\
\hline 3Group & $\begin{array}{c}\text { Factor 1 } \\
\text { 4Group }\end{array}$ & $\begin{array}{c}\text { Greenhouse- } \\
\text { Geisser }\end{array}$ & 7.651 & .007 & .061 & .783 \\
\cline { 2 - 7 } & $\begin{array}{c}\text { Factor 1 } \\
* \text { Event }\end{array}$ & $\begin{array}{c}\text { Greenhouse- } \\
\text { Geisser }\end{array}$ & .271 & .604 & .002 & .081 \\
\hline \hline
\end{tabular}

\section{가설 검정}

가설에 대한 검증은 혼합설계(Mixed Design)를 사용 하여 검증 하였다. 검증 시, 개체내 변인은 사전조사 $\left(\mathrm{Pre}^{-}\right.$ test)의 평균값과 사후조사(Post-test)의 평균값이 투입 되었다. 이와 함께 개체 간의 변인으로는 노출의 순서가 (선노출(0)과 후노출(1)로 코딩) 투입 되었다. 이때 사후 조사(Post-test)의 평균값이 사전조사(Pre-test)보다 통 계적으로 높게 나타난다면 이미지의 전이가 이루어 진 것 을 의미한다. 즉 스폰서십을 통해 이벤트의 이미지가 브 랜드로 전달이 되었다는 것을 의미한다. 정보노출 순서, 정보노출 간격에 대한 사전조사 및 사후조사의 평균값은 〈Table 7〉과 같다.

가설 $1 \mathrm{a}$ 와 $1 \mathrm{~b}$ 그리고 가설 $2 \mathrm{a}$ 와 $2 \mathrm{~b}$ 는 같은 분석 방법 을 사용하여 검증되었다. 기술통계에서 제시되는 평균 값에서 선노출된 집단의 평균값의 차이가 후노출된 집단 의 평균값의 차이보다 통계적으로 크게 나타난다면 이는 가설 $1 \mathrm{a}$ 와 $1 \mathrm{~b}$ 를 지지하게 된다. 그러나 가설 $2 \mathrm{a}$ 와 $2 \mathrm{~b}$ 의 검증에서는 후노출된 집단의 평균의 차이가 선노출된 집 단의 평균차보다 높게 나타나고 이 차이가 통계적으로 유의하게 나타날 경우에 가설 $2 \mathrm{a}$ 와 $2 \mathrm{~b}$ 에 대한 지지가 이 루어진다. 
Table 7. Brand image from the Pre-test and the Post-test

\begin{tabular}{|c|c|c|c|c|c|}
\hline & $\begin{array}{l}\text { Exposure } \\
\text { sequence }\end{array}$ & Exposure interval & $M$ & $S D$ & $N$ \\
\hline \multirow{9}{*}{ Pre-test } & \multirow{3}{*}{$\begin{array}{l}\text { Early in } \\
\text { sequence }\end{array}$} & Immediately & 4.57 & .94 & 60 \\
\hline & & 2 days & 4.61 & .99 & 60 \\
\hline & & Overall & 4.59 & .96 & 120 \\
\hline & \multirow{3}{*}{$\begin{array}{l}\text { Later in } \\
\text { sequence }\end{array}$} & Immediately & 4.58 & 1.00 & 60 \\
\hline & & 2 days & 4.89 & 1.12 & 60 \\
\hline & & Overall & 4.74 & 1.07 & 120 \\
\hline & \multirow{3}{*}{ Overall } & Immediately & 4.58 & .97 & 120 \\
\hline & & 2 days & 4.75 & 1.06 & 120 \\
\hline & & Overall & 4.67 & 1.02 & 240 \\
\hline \multirow{9}{*}{ Post-test } & \multirow{3}{*}{$\begin{array}{l}\text { Early in } \\
\text { sequence }\end{array}$} & Immediately & 5.30 & 1.17 & 60 \\
\hline & & 2 days & 4.67 & 1.25 & 60 \\
\hline & & Overall & 4.99 & 1.25 & 120 \\
\hline & \multirow{3}{*}{$\begin{array}{c}\text { Later in } \\
\text { sequence }\end{array}$} & Immediately & 4.96 & 1.20 & 60 \\
\hline & & 2 days & 5.39 & 1.07 & 60 \\
\hline & & Overall & 5.18 & 1.16 & 120 \\
\hline & \multirow{3}{*}{ Overall } & Immediately & 5.13 & 1.19 & 120 \\
\hline & & 2 days & 5.03 & 1.21 & 120 \\
\hline & & Overall & 5.08 & 1.20 & 240 \\
\hline
\end{tabular}

본 연구의 가설을 검증하기 위하여 사용 되어진 혼합 설계 (Mixed Design)에서는 개체 간, 요인들 간의 상호 작용효과가 검증되어야 한다. 따라서 각 조절 변인에 대 한 주효과를 검토하기 전에 상호작용에 대한 검증이 선 행되어야 한다. 만약 상호작용이 통계적으로 유의하게 나 타나면 각 조절 변인에 대한 주효과는 해석하지 않는다. 개체 간 효과 검정 결과는 〈Table 8)과 같다.

조절변인이 두 개 이상인 경우 상호작용이 발생하는데 분석 결과에서 개체 간(두 개의 조절변인 간)의 상호작용 효과가 통계적으로 유의하게 나타났다 $(F=7.932 p=$
.005, Fig. 1과 Fig. 2 참조). 분석 결과에 따르면 스포츠 이벤트 이미지가 전이 되는데 있어서 노출순서의 효과는 즉시노출집단과 2 일간의 간격 후 노출집단에서 다르게 나타났다. 선노출된 스포츠 이벤트의 이미지 전이 효과는 노출간격에 의해 조절이 되었지만 후노출된 스포츠 이 벤트에서는 노출된 간격에 따른 주효과가 나타나지 않 았다.

선노출과 후노출된 스포츠 이벤트에서 이미지 전이의 정도는 선노출과 후노출을 시간의 간격 없이 노출시켰을 때와 2 일이라는 간격을 두었을 때 다르게 나타났다. 시간 의 간격이 없이 선노출과 후노출이 이루어진 경우, 사전 조사(Pre-test)에서는 두 집단이 거의 동일한 평균을 보 였지만 사후조사(Post-test)에서는 선노출된 스포츠 이 벤트의 이미지 전이가 더 크게 나타났다. 하지만 선노출과 후노출의 효과는 2 일이라는 간격을 둔 집 단에서는 전혀 반대의 결과를 보여주고 있다. 선노출과 후노출 사이에 2 일의 간격을 둔 집단에서는 후노출 스포츠 이벤트에서 이 미지 전이가 더 많이 이루어진 것을 알 수 있다<Fig. 4, Table 9$\rangle$.

\section{논 의}

본 연구에서는 고비용의 광고를 대체하는 수단으로 자리를 잡게 된 스포츠스폰서십의 효과적인 실행을 위해 고려해야 할 변인들에 대해 탐색 하였다. 본 연구의 변인 으로 선택된 정보노출 순서와 정보노출 시간의 간격이 스포츠 이벤트가 가지고 있는 이미지가 브랜드로 전이되 는데 있어서 어떠한 영향을 미치는지를 알아보았다. 이를 위해 예비조사 일 회, 본 조사 일 회를 실시하였다. 본 연 구에 대한 결과와 함께 본 연구의 과정에서 제시된 다양 한 사안에 대한 논의를 다음과 같이 제시한다.

Table 8. Between-factor effect test result of exposure sequence and exposure interval

\begin{tabular}{|c|c|c|c|c|c|c|c|}
\hline & & $\begin{array}{c}\text { Type III } \\
\text { Sum of square }\end{array}$ & $d f$ & $M S$ & $F$ & $p$ & Power \\
\hline Factor 1 (Pre, Post) & Greenhouse-Geisser & 20.695 & 1 & 20.69 & 34.677 & .000 & 1.000 \\
\hline Factor $1 *$ Sequence & Greenhouse-Geisser & .052 & 1 & .05 & .087 & .768 & .060 \\
\hline Factor $1 *$ Interval & Greenhouse-Geisser & 2.178 & 1 & 2.17 & 3.650 & .057 & .477 \\
\hline Factor $1 *$ Sequence $*$ Interval & Greenhouse-Geisser & 4.734 & 1 & 4.73 & 7.932 & .005 & .801 \\
\hline
\end{tabular}




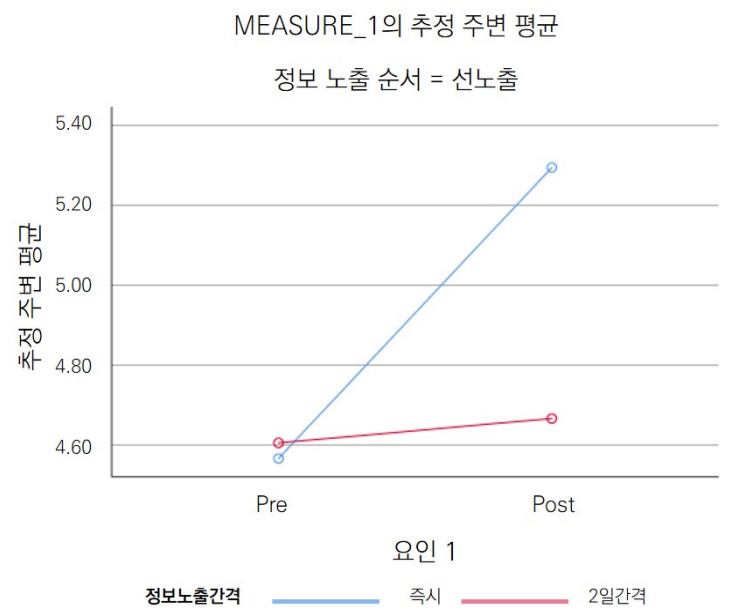

Fig. 1. Moderating effect of exposure interval on main effect of within-subjects(Pre, Post) with early in sequence

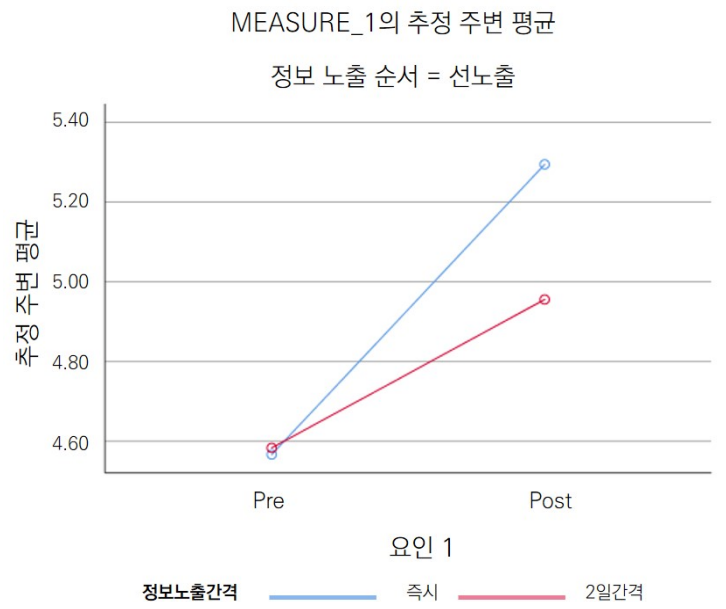

Fig. 3. Moderating effect of exposure sequence in main effect of within-subjects(Pre, Post) with immediate exposure

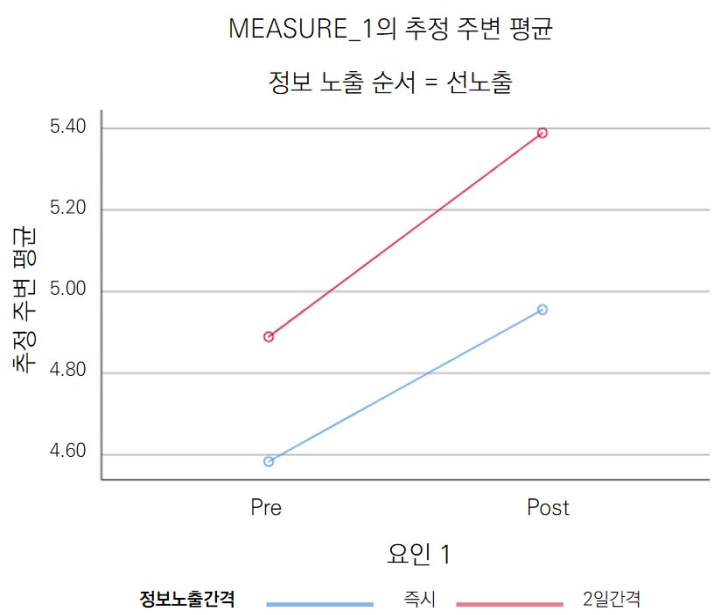

Fig. 2. Moderating effect of exposure interval on main effect of within-subjects(Pre, Post) with later in sequence

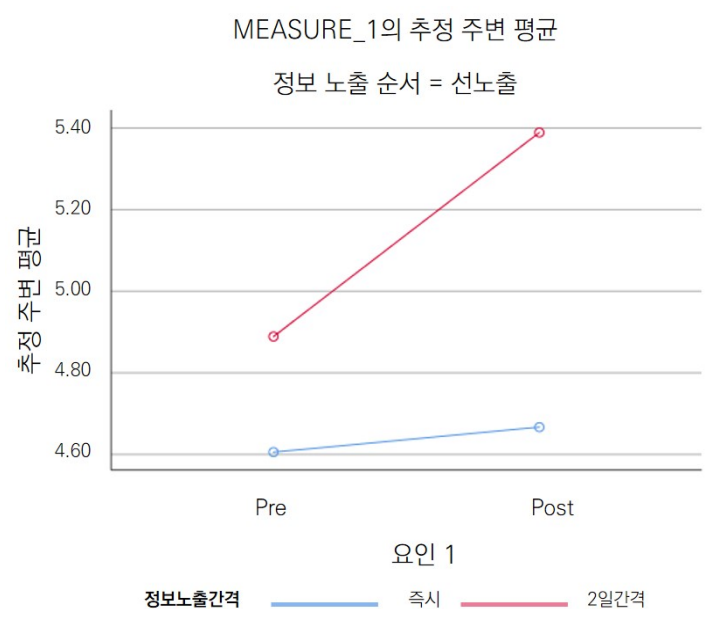

Fig. 4. Moderating effect of exposure sequence in main effect of within-subjects(Pre, Post) with 2 days interval

Table 9. Statistical significance test of estimated marginal mean

\begin{tabular}{|c|c|c|c|c|c|c|c|c|}
\hline \multirow{2}{*}{ Sequence } & \multirow{2}{*}{ Factor 1} & \multirow{2}{*}{$\begin{array}{l}\text { (I) Exposure } \\
\text { Interval }\end{array}$} & \multirow{2}{*}{$\begin{array}{l}\text { (J) Exposure } \\
\text { Interval }\end{array}$} & \multirow{2}{*}{$\begin{array}{c}\text { Mean } \\
\text { difference (I-J) }\end{array}$} & \multirow{2}{*}{$\mathrm{SE}$} & \multirow{2}{*}{$p$-value } & \multicolumn{2}{|c|}{$95 \%$ probability range of the difference } \\
\hline & & & & & & & Lowest & Upper \\
\hline \multirow{4}{*}{ Early } & \multirow{2}{*}{ Pre } & Immediately & 2 days & -.039 & .185 & .834 & -.404 & .326 \\
\hline & & 2 days & Immediately & .039 & .185 & .834 & -.326 & .404 \\
\hline & \multirow{2}{*}{ Post } & Immediately & 2 days & .628 & .215 & .004 & .205 & 1.051 \\
\hline & & 2 days & Immediately & -.628 & .215 & .004 & -1.051 & -.205 \\
\hline \multirow{4}{*}{ Later } & \multirow{2}{*}{ Pre } & Immediately & 2 days & -.306 & .185 & .100 & -.670 & .059 \\
\hline & & 2 days & Immediately & .306 & .185 & .100 & -.059 & .670 \\
\hline & \multirow{2}{*}{ Post } & Immediately & 2 days & -.433 & .215 & .045 & -.856 & -.010 \\
\hline & & 2 days & Immediately & .433 & .215 & .045 & .010 & .856 \\
\hline
\end{tabular}


먼저 본 연구의 자료를 수집한 대상인 표본에 관련된 논의이다. 본 연구의 표본은 과거 유사한 연구(Baeck, 2017; Kwon, Li \& Choi, 2018)와 달리 다양한 인구통 계학적 특성을 갖는 연구대상자를 선정하였다. 기존의 연 구에서 대학생들을 대상으로 자료를 구한 것은 연구 결 과가 가지는 외적타당도의 제약일 수밖에 없고 이는 연 구 결과를 현장에 적용하는데 있어 장애가 될 수 있다. 따라서 본 연구에서는 스폰서십에서의 이미지 전이를 다 양한 인구통계학적특성을 지닌 연구 참여자를 대상으로 확인하였다는 점에서 큰 의의를 가진다고 할 수 있다. 특 히 본 예비조사에서는 과거 실증연구에 사용되었던 표 본인 20 대 연구 참여자를 최소한으로 제한하면서 다양 한 연령대의 참여자를 확보하려고 노력하였다. 또한 본 조사에서도 충분한 소비를 할 수 있는 가처분 소득이 가 장 안정적으로 확보될 수 있는 40 대 직장인 연구 참여자 를 충분히 확보하여 본 연구의 현장 적용성을 높이도록 노력하였다. 물론 이론의 효과를 검증하는데 있어서 동 질의 표본을 이용하는 것이 좋다는 문헌(Zhou, Teng \& Poon, 2008)이 존재하지만, 본 연구에서는 $\operatorname{Baeck}(2017)$, Kwon et al. (2018)에서 이미 실증적으로 확인된 이미지 전이의 효과가 다양한 인구통계학적 특성을 갖는 연구 참 여자에게서도 나타나는지를 보여줬다는 측면에서 추가 적인 연구의 의의를 갖는다.

다음으로 본 연구의 연구설계에 대한 논의이다. 본 연 구의 실험설계에서는 가외변인에 의한 실험결과의 오염 이 발생하지 않도록 많은 노력을 기울였다. 먼저 종속 변인에 영향을 미칠 가능성을 갖고 있는 성별과 종목에 따른 이미지 전이의 차이가 있는 지를 확인하였다. 이는 $\mathrm{TV}$ 스포츠 중계 프로그램에서 종목에 대한 선호도가 성 별에 따라 다르다는 조사기관의 연구결과에 기인한 것이 다(Jeon, Kim \& Hong, 1995). 또한 베이징올림픽을 앞 두고 올림픽 종목에서 가장 좋아하는 종목을 조사한 결 과 성별에 따라 선호 종목이 뚜렷하게 다르다는 보고가 있었다(Gwon, 2008). 따라서 성별과 종목이 종속변인 에 영향을 미치는지의 여부를 확인하는 절차를 진행하여 가외변인으로부터 안전한 자료인지를 확인함으로써 실 험결과의 타당도를 높였다.

선행연구들은 스폰서 브랜드와 스포츠 이벤트의 유사 성이 높을수록 스폰서십을 통한 이미지 전이가 강하게 일 어난다고 하였다(Kim et al., 2006; Kim et al., 2010; Baeck, 2017; Lee \& Hyun, 2010; d’Astous \& Bitz,
1995; Gwinner \& Eaton, 1999; McCracken, 1989; Misra \& Beatty, 1990; Simmons \& Becker-Olsen, 2006). 대부분의 연구는 스폰서십 브랜드와 스포츠 이벤 트간의 이미지의 유사성과 이미지 전이의 정도를 알아 보았다(Kim et al., 2006; Kim et al., 2010; Baeck, 2017; Lee \& Hyun., 2010; Gwinner \& Eaton, 1999; McCracken, 1989). 하지만 본 연구에서는 이미지 전이 를 확인하기 위하여 사격대회와 수영대회라는 서로 이질 적인 이미지의 스포츠 이벤트를 선정하였고, 선정된 스포 츠 이벤트들과 유사성이 낮은 브랜드로 DELL을 선정하 였다. 물론 형용사를 선택하는 과정에서 세계수영선수권 대회와 세계사격선수권대회에 '긴장감 있는' , '열정적인', '강인한', '멋진'의 평균값이 공통적으로 높게 나타났다. 공통적으로 존재하는 형용사로는 이미지 전이를 확인할 수 없기 때문에 가설검증에서는 제외되고 차 순위의 형용 사를 각각 선택하여 두 집단의 형용사에 공통적으로 존재 하는 형용사가 존재하지 않도록 하였다. 세계수영선수권 대회와 연계된 형용사로는 '쾌활한', '건전한' '활발한'이 라는 형용사를 최종적으로 선택하였고 세계사격선수권 대회의 형용사로는 '차분한', '격식 있는', '섬세한'이라는 형용사를 선택하여 두 이벤트가 상당히 이질적인 이벤트 로 연구 참여자들에게 인식되게 하였다. 또한 스폰서십에 참여하는 브랜드로 선정된 DELL의 경우 '기술적인'이라 는 형용사가 세 번째로 평균점수를 타나내었다. '기술적 인'은 세계사격선수권대회에서는 여섯 번째로 높은 평균 값으로 나타났으나 그 외에는 두 개의 스포츠 이벤트들과 공유되는 형용사는 없었다. 따라서 DELL의 형용사 세 개를 선택하는 데 있어서 '기술적인'만 제외를 하고 평균 이 높게 나온 형용사 '성 공한, '현대적인', '창의적인'을 선 택하였다. 즉 스폰서 브랜드가 두 개의 스포츠 이벤트와 상당히 다른 이미지를 보유한 것으로 나타났다.

이렇듯 본 연구는 선행연구와 달리 스폰서십을 실행하 는 브랜드와 스포츠 이벤트와의 이미지 유사성이 배제되 었다. 이질적인 이미지를 보유한 스폰서 브랜드와 스포츠 이벤트 사이의 이미지 전이는 과거에 제시되었던 이미지 전이 관련 실증연구들이 제공하지 못했던 가장 큰 약점을 보완했다는 측면에서 큰 의의가 있다.

다음은 연구 결과에 대한 논의이다. 자료의 분석결과 다수의 선행연구에서 나타난 바와 같이 본 연구에서도 스 폰서십에 의한 이미지 전이가 일어난 것을 확인 하였다. 애초에 브랜드에 없었던 이미지가 스포츠 이벤트를 통해 
전이된 것으로 판단된다.

일반적으로 스폰서십을 통해 이미지 전이의 효과를 보 고자 하는 스폰서들은 자기 브랜드가 갖고 있지 못한 이 미지를 스포츠 이벤트로부터 전달받기 위해 상당한 비용 을 지불하는 것이다. 스폰서십이 보유한 그러한 목적이 존재하는데도 불구하고 이미지가 유사한 스폰서 브랜드 와 이벤트에서만 이미지의 전이가 일어난다는 실증적 결 과(Gwinner \& Eaton, 1999)는 스폰서십의 화폐적 가치 를 오히려 떨어뜨릴 가능성이 존재한다. 이러한 측면에서 볼 때 본 연구는 이미지의 유사성이 존재하지 않은 스폰 서들도 그들이 원하는 이미지를 보유하고 있는 이질적인 스포츠 이벤트를 통해 원하는 이미지를 전이 받을 수 있 다는 것에 대한 근거를 제시하였다.

자료 분석 결과 독립변인으로 투입된 정보노출 순서와 정보노출 시간 간격에 따른 상호작용이 나타났다. 자료의 분석 결과에 따르면 〈Fig. 1〉에서 나타났듯이, 선노출된 스포츠 이벤트의 이미지 전이 정도는 즉시 두 번째 이벤 트를 노출하였을 때가 2 일의 간격을 두고 노출하였을 때 보다 훨씬 크게 나타났다. 이는 초두효과의 영향이라고 판단된다. 이와 달리, 후노출된 스포츠 이벤트의 경우에 는 첫 번째 이벤트와 두 번째 이벤트를 연속해서 차례로 노출하였을 때 보다 2 일간의 간격을 두고 노출하였을 때, 이미지 전이가 더 크게 나타났다〈Fig. 4〉. 이는 선노출된 스포츠 이벤트에 대한 이미지는 상대적으로 적게 전이가 된 것이다. 즉 가설의 도출과정에서 제시된 최신효과의 영향이 나타났다고 할 수 있다.

정보노출 순서에 따른 효과와 관련한 심리적인 메카니 즘은 추후 자세한 연구가 필요하겠으나, 본 연구 결과를 바탕으로 효과적인 마케팅 방법을 제안할 수 있다. 예를 들어 모든 스폰서십 정보를 한꺼번에 노출하게 되는 자사 의 홈페이지를 통해서는 초두효과를 기대 할 수 있다. 자 세히 설명하자면 스폰서십 정보를 노출할 때 스폰서십을 실행한 년도 순으로 나열할 것이 아니라, 가장 부각시키 고 싶은 이미지를 소유한 스포츠 이벤트 정보를 앞쪽에 게재하는 것이다. 특히 웹페이지의 화면을 응시하는 순서 가 일반적으로 좌측 상단부터 우측 하단으로 이동되는 것 을 고려하여 화면 상단을 이용한다면 초두효과로 인해 전 략적으로 부각시키고 싶은 이미지를 효과적으로 전달 할 수 있을 것으로 판단된다.

본 연구는 정보노출에 대한 시간을 조작함으로써 최 신효과를 예측할 수 있다는 결과를 제시하였다. 이와 유
사하게 Miller와 Campbell(1959)은 망각에 따른 이론 을 근거로 정보노출과 태도형성간의 시간을 조작한 연구 에서 최신효과를 입증하였다. 이 연구에서 나타난 최신 효과는 처음에 노출된 정보가 장기기억에서 검색 될 때 나중 노출된 정보가 작업 기억에 있어서 처음에 노출된 정보의 회상을 간섭할 수 있기 때문인 것으로 주장되었 다. 이에 사전에 관여된 스포츠 이벤트의 이미지보다는 현재 진행되고 있는 이벤트나 미래에 있을 스포츠 이벤 트의 이미지를 더 전이 받고 싶다면 최신효과를 충분히 가져올 수 있도록 사전에 관여된 스폰서십에 대한 노출 이 끝난 후 어느 정도의 시간을 두고 시행하는 것을 제안 한다. 즉, 충분한 시간적 간격을 두고 새로운 스폰서십 에 대한 정보를 노출시킬 필요가 있다. 본 연구에서는 2 일의 시간적 간격을 두었지만 실제 시장상황에서 얼마 의 시간적 간격이 적절할 지는 향후 충분한 연구가 필요 하다.

\section{결론 및 제언}

본 연구의 목적은 기업이 구축하고자 하는 이미지에 맞춰 스포츠 스폰서십을 실행하는데 있어서 관련된 변 인들이 이미지 전이에 어떻게 작용하는지를 알아보는 것 이었다. 이에 따라 본 연구에서는 다양하게 실행되는 스 폰서십이 소비자들에게 노출되는 순서와 시간 간격에 따 라 스포츠 이벤트의 이미지 전이가 다르게 이루어진다 는 것을 확인하였다. 가설 검정에 앞서 성별과 스포츠 종 목 두 가지의 가외변인이 이미지 전이에 있어서 조절효과 가 나타나지 않음을 확인하였다. 가설은 혼합설계 (Mixed Design)를 사용하여 검정 하였는데, 요인들 간의 상호작 용효과가 통계적으로 유의하게 나타났다. 자료의 분석 결 과에 따르면 다른 이미지를 소유한 두 개의 스포츠 이벤 트들에 대한 정보를 시간의 간격 없이 연속해서 노출하 였을 때는 선노출된 스포츠 이벤트의 이미지가 더 많이 스폰서 브랜드로 전이된 것으로 나타났다. 이로써 초두효 과를 확인할 수 있었으며 두 개의 스포츠 이벤트를 2 일 이라는 간격을 두고 노출하였을 때는 다른 결과가 나타 났다. 두 개의 스포츠 이벤트를 연속하여 노출 하였던 것 과는 반대로 후노출된 스포츠 이벤트의 이미지가 스폰서 브랜드로 더 많이 전이 된 것으로 나타났다.

본 연구는 스폰서 브랜드와 스포츠 이벤트가 서로 이 
미지가 다른 경우에도 스포츠 이벤트가 가지고 있는 특 정한 이미지가 스폰서 브랜드로 전이되는 것을 확인하였 다. 이러한 결과를 토대로 하여 초두효과와 최신효과를 바탕으로 실제 마케팅 상황에서 적용할 수 있는 몇 가지 의 방법을 제안하였다. 이렇듯 연구 결과가 현장에 적용 될 수 있는 가능성을 높이도록 노력하였으나 연구결과를 일반화하기에는 몇 가지 한계점이 존재한다.

본 연구의 가장 큰 한계점은 스포츠 이벤트를 통한 스 폰서십정보가 실험실 상황에서 전달된 것이다. 물론 스포 츠 이벤트를 통한 스폰서십 정보가 순서대로 전달되며 명 확하게 전달 될 수 있도록 인터넷 기사를 출력한 형태의 제작물을 사용하였다. 이와 관련하여 Park et al. (2012) 은 메시지의 유형과 노출순서의 상호작용에 따른 효과를 제시하였다. SNS의 광고 유형과 잡지 매체의 경우 노출 순서에 따라 광고효과가 달라진다는 것이다. 또한 단일 매체 보다 복합 매체를 사용하는 것이 기억에서 효과적일 것이라는 주장이 있다 $(\mathrm{Ku}, 2005)$. 이와 더불어 신문, 잡 지, 옥외 광고 등 여러 광고형태를 복합적으로 활용할 때 광고 기억, 브랜드 태도, 광고 태도 등에서 유의미한 결과 를 보고한 연구가 있다(Lee \& Kim, 2009; Cho, Roh \& Hong, 2018). 이러한 연구결과를 볼 때 향후 진행되는 연 구가 실험실 상황에서의 연구라면 스폰서십 정보가 효과 적으로 전달 되도록 하기 위하여 다양한 유형의 매체를 동시에 사용할 필요가 있다.

본 연구의 실험은 연구대상자들에게 노출되는 스포츠 이벤트의 순서를 조작하였다. 이때 이미지 전이에 영향을 미치는 요인으로 친숙도를 고려하였다. 이는 사전조사를 통해 친숙도가 비슷한 수준의 스포츠 이벤트를 선정하는 절차를 통해 충분히 통제가 되었다고 판단된다. 그러나 본 연구에서는 연구 참여자들이 가지고 있을 종목에 대한 관여도를 고려하지 못했다.

관여도는 초두효과와 최신효과의 작용에 영향을 미치 는 것으로 보고되고 있다(Doo, 2011). Doo에 따르면 제 품에 대한 관여도가 높을 때는 초두효과가 더 강하게 작 용하고, 제품에 대한 관여도가 낮을 때는 최신효과가 더 강하게 작용한다는 것이다. 관여도는 정보노출의 간격 과도 작용을 하는데 관여도가 낮은 경우 정보노출의 간 격이 짧을 때 최신효과가 작용하는 것으로 설명되고 있 다. 따라서 향후 연구에서는 관여도를 추가적으로 고려한 연구가 실증적으로 이루어질 필요가 있다.

마지막으로 현장 적용성에 관계된 부분이다. 과거 유
사한 연구와 달리 다양한 인구통계학적 특성을 갖는 연구 대상자를 선정하였고, 가처분 소득이 가장 안정적으로 확 보될 수 있는 40 대 직장인을 연구 참여자로 충분히 확보 하였다. 하지만 한 개의 스폰서 브랜드와 두 개의 스포츠 이벤트를 통해 도출한 결과를 일반화 하는 데는 한계가 존재하기 때문에 향후 유사한 많은 연구들의 결과들이 축 적될 필요가 있다.

\section{참고문헌}

Aaker, J. L. (1997). Dimensions of brand personality. Journal of Marketing Research, 34(3), 347-356.

Asch, S. E. (1946). Forming impressions of personality. The Journal of Abnormal and Social Psychology, 41(3), 258 290.

Baeck, J. H. (2017). Examining Image Transfer in Sponsorship Using Pre-Post test design. Unpublished Masters dissertation. Chung-Ang University.

d'Astous, A., \& Bitz, P. (1995). Consumer evaluations of sponsorship programmes. European Journal of Marketing, 29(12), 6-22.

Doo, J. W. (2011). The Impact of Pioneer Status and Exposureorder on Consumers' Brand Preference: Mediated Effects of Involvement and Product Characteristics. Korea Business Review, 26, 413-440.

Choi, D. H. (2003). The Effects of a Preceding TV Advertisement on the Process of Forming Attitudes toward the Following advertisement. Unpublished Ph. D dissertation. Inje University.

Cho, J. S., Roh, J. Y., \& Hong, H. H. (2018). Examining the Synergy Effect of Brand Messages via Multiple Media: Focusing on the Effect of Magazine-Online Combination Among Female Consumers in 20s and 30s. Advertising Research, (116), 38-83.

Choi, Y. J. (2008). Order and Proportion Effects of Scenes in a Broadcasting News Story, and a Moderating Role of Image-Issue. Korean Journal of Broadcasting and Telecommunication Studies, 22(3), 365-396.

Gladden, J. M., \& Wolfe, R. (2001). Sponsorship of intercollegiate athletics: The importance of image matching. International Journal of Sports Marketing and Sponsorship, 3(1), 29-53.

Graeff, T. R. (1996). Image congruence effects on product evaluations: The role of self-monitoring and public/private consumption. Psychology \& Marketing, 13(5), 481-499.

Gwinner, K. (1997). A model of image creation and image trans- 
fer in event sponsorship. International Marketing Review, 14(3), 145-158.

Gwinner, K., \& Eaton, J. (1999). Building brand image through event sponsorship: The role of image transfer. Journal of Advertising, 28(4), 47-57.

Gwon, O. S. (2008. 7. 18). 올림픽 선호종목, 남녀 뚜렷이 갈려. Hankyoreh. Retrieved October 8, 2018, from http://www.hani. co.kr/arti/sports/sports_general/299559.html\#csidxac3f5596 692d284a027574a379ade80

Hanwha (2017). Sports \& Sponsorship. Retrieved May 1, 2017, from https://www.hanwha.co.kr/utility/sports.do

Hwang, J. W., \& Kim, K. H. (2018. 4. 7). 금융사 스포츠마케 팅... 어떤 비밀 숨어 있나. Sedaily. Retrieved May 1, 2018, from http://www.sedaily.com/NewsView/1RY5VIZ5JS

Jeon, G. C., Kim, Y. R., \& Hong, S. A. (1995). Research on TV sports program and watching behavior. Seoul: Korean Broadcasting Institute.

Jung, J. P. (2009). The Ballot Order Effect in the 2006 Municipal Council Elections and Its Implications. Korean Journal of Political Science, 17(2), 395-422.

Jung, W. S. (2016). The Moderate Effect by Region in the Ballot Order Effect: Empirical Analyses of 2010 and 2014 Education Superintendent Elections in Korea. Journal of Local Government Studies, 28(1), 129-153.

Kim, B. S. (2011). Ballot Position Effect in the 2010 Education Committee Election, in Korea. East and West Studies, 23(1), 65-101.

Kim, D. H., Shim, S. W., \& Kim. J. S. (2010). What Happens When the Apple Sponsors the Orange?: Congruent and Incongruent Matches of Brands with Events and Image Transfer Effect. The Korean Journal of Advertising, 21(6), 183-205.

Kim, K. S., Lee, S. G., \& Lee, Y. G. (2006). A Study of Transferring Image between Brand and Event on Sponsorship: Focusing on the Similarity of Attribute in Brand and Event. The Korean Journal of Advertising, 17(5), 143-153.

Kim, S. W., Cho, H. B., \& Kim, I. J. (2010). The Effect of Title Sponsorship of Tennis Championship on a Brand and an Image of Enterprises. Korean Journal of Sport Management, 15(2), 55-75.

Kline, R. B. (1998), Principles and Practice of Structural Equation Modeling, New York, NY: Guilford Press.

Ku, G. T. (2005). A Study of Media Use on Advertising Brand and Message Recall. Journal of Communication Science, 5(2), 5-32.

Kwon, H. I., \& Cho, Y. J (2017). The Analysis of Image Transfer
Mechanism in CRM through Sport Team: The Effects of Frequency of Information Exposure and Image of Sponsors. Korean Journal of Sport Science, 28(1), 155-166.

Kwon, H. I., Li, B. X., \& Choi, M. H. (2018). Transfer of specific images through sport sponsorship and the moderation effect of relevance between a sport event and a sponsor brand. Korean Society of Sport Management, 23(4), 1-16.

Kwon, H. J. (2017. 12. 27). K리그스폰서십 노출효과. Joongang Ilbo, Retrieved May 5, 2018, from http://news.joins.com/article/ 22237373

Lana, R. E. (1961). Familiarity and the order of presentation of persuasive communications. The Journal of Abnormal and Social Psychology, 62(3), 573-577.

Lee, H. J., \& Hyun, Y. J. (2010). An Analysis of the Effect of Sport Sponsorship through Image Transfer. Korean Journal of Sport Management, 15(5), 1-15.

Lee, W. C., \& Kim, G. H. (2009). Suitability Study on Media Message Mix for Advertising Synergy Maximization. Journal of Public Relations, 13(2), 70-98.

Machleit, K. A., Allen, C. T., \& Madden, T. J. (1993). The mature brand and brand interest: An alternative consequence of ad-evoked affect. The Journal of Marketing, 57(4), 72-82.

McCracken, G. (1989). Who is the celebrity endorser? Cultural foundations of the endorsement process. Journal of Consumer Research, 16(3), 310-321.

Misra, S., \& Beatty, S. E. (1990). Celebrity spokesperson and brand congruence: An assessment of recall and affect. Journal of Business Research, 21(2), 159-173.

Miller, N., \& Campbell, D. T. (1959). Recency and primacy in persuasion as a function of the timing of speeches and measurements. The Journal of Abnormal and Social Psychology, $59(1), 1-9$.

Nam, I. Y., \& Chung, S. H. (2016). 이성설득전략. Seoul: CommunicationBooks.

Park, S. Y., Kim, J. H., \& Kim, G. H. (2012). The Synergy Impact of using SNS according to Exposure Order on Media Mix: Interaction of SNS advertising type. Korean Journal of Consumer and Advertising Psychology, 13(2), 255-281.

Ryoo, C. H., Bae, S. H., Hong, Y. K., Park, S. H., Choi, C. J., Park, M. C., Back, S. J., You, J. S., \& Kim, J. A., (2015). The response of visual and verbal information in advertising design - Focused on fMRI. Korean Society of Basic Design \& Art, 16(4), 181-190.

Sol, Y. H. (2016). An effective review method based on Ebbinghaus's oblivious curves. Journal of Learning Strategy 
Intervention, 7(1), 1-18.

Song, J. S., Jung, W. H., Choo, J. H., Chung, K. M., \& Jung, W. S. (2014) Important Perceptual and Cognitive Factors to Include in Apology E-mails to Dissatisfied customers. The Korean Journal of Cognitive and Biological Psychology, 26(2), 95-132.
Simmons, C. J., \& Becker-Olsen, K. L. (2006). Achieving marketing objectives through social sponsorships. Journal of Marketing, 70(4), 154-169.

Zhou, L., Teng, L., \& Poon, P. S. (2008). Susceptibility to global consumer culture: A three-dimensional scale. Psychology \& Marketing, 25(4), 336-351.

\section{스포츠 스폰서십에서 노출순서와 노출의 시간적 간격에 따른 이미지 전이 효과: 초두효과와 최신효과의 검증}

\section{권형일 · 최미화(중앙대학교)}

〔목적〕 본 연구는 스포츠 스폰서십 상황에서 스포츠 이벤트에 대한 정보가 노출되는 순서와 간격(시간)에 따라 각각의 스포츠 이벤트가 가지고 있는 고유한 이미지가 스폰서십을 실행하는 브랜드에 다르게 전이되는지 에 대하여 확인하고자하였다. (방법) 예비 조사 일 회와 본 조사 일 회를 실시하였는데, 예비 조사 33명, 본 조사 120 명의 자료가 분석에 사용되었다. 본 연구의 자료는 SPSS 23 을 이용하여 일표본 t-test, 기술통계 분석, 혼합설계(Mixed Design)를 실시하였다. [결과) 개체 내 변인과 개체 간 변인 두 변인들 간의 상호작용 효과가 통계적으로 유의하게 나타났다. 이는 스폰서 브랜드와 스포츠 이벤트 사이에 공통되게 인지된 형용사 를 의도적으로 배제하여 스폰서 브랜드에 스폰서십을 실행한 결과 애초에 존재하지 않았던 이미지들이 스폰서 십을 통해서 브랜드로 전이 된 것을 의미한다. 자료의 분석 결과에 따르면 두 개의 스포츠 이벤트들에 대한 정보를 시간의 간격 없이 연속해서 노출하였을 때는 선노출된 스포츠 이벤트의 이미지가 스폰서 브랜드로 더 많이 전이된 것으로 나타나 초두효과를 예측할 수 있다. 반면 두 개의 스포츠 이벤트를 2 일이라는 간격을 두고 노출하였을 때는 후노출된 스포츠 이벤트의 이미지가 스폰서 브랜드로 더 많이 전이되어 최신효과를 예상할 수 있다. 〔결론) 본 연구의 결론으로는 두 가지가 제시될 수 있다. 첫째, 스폰서 브랜드와 스포츠 이벤트간의 이미지 유사성이 없는 경우에도 스포츠 이벤트의 이미지는 스폰서 브랜드로 전이된다는 것이 경험적으로 증명 이 되었다. 둘째, 스폰서십을 실행할 때 초두효과와 최신효과가 고려된다면 브랜드가 추구하는 이미지를 더욱 효과적으로 소비자들에게 전달할 수 있다.

주요어: 스폰서십, 이미지 전이, 초두효과, 최신효과 